\title{
Reversible enhanced upconversion luminescence by thermal and electric fields in lanthanide ions doped ferroelectric nanocomposites
}

\author{
Er Pan, Gongxun Bai ${ }^{*}$, Bingrong Ma, Lei Lei, Lihui Huang and Shiqing Xu
}

\begin{abstract}
Luminescence modification of lanthanide ions has attracted great attention due to its applications in sensing, colorful display, information transmission and anti-counterfeiting. Traditional methods of tuning fluorescence typically employ tuning compositions that are not conducive to the development of multi-environment detection and anti-counterfeiting. In this study, lanthanide ions doped ferroelectric nanocomposite was exploited with external stimuli. The upconversion luminescence modification was preformed via both the thermal and electric fields. The anti-thermal quenching phenomenon was observed in the prepared nanocomposite, which could effectively enhance the upconversion luminescence of lanthanide ions. Based on the electromechanical softness of the ferroelectric lattice, exceptional luminescence modification was realized through electric polarization. The luminescence modifications by thermal and electric fields exhibited excellent reversibility and non-volatility. These results provide unique insights into the development of integrated stimulus responsive smart devices, colorful display and advanced multi-mode sensing materials.
\end{abstract}

Keywords: upconversion, lanthanide, temperature, electric field, ferroelectric

\section{INTRODUCTION}

In recent years, the upconversion luminescent materials with lanthanide ions have drawn great attention due to their practical and promising applications in the areas of anti-counterfeiting, solid-state multicolor display and biomarker [1-8]. Lanthanide ions doped fluorides and oxides with tunable luminescence have been extensively studied in many host materials. Those reports mainly focused on chemical methods such as tailoring the concentration of dopant or modulating the composition of host. However, it is difficult to separate pure crystal field transformation from internal effects in different samples such as chemical inhomogeneity and crystal defects. In addition, luminescence modification by chemical methods is generally irreversible and volatile, impeding the exploration of the dynamic physical processes of luminescence and the discovery of new photonics application. Hence, the utilization of external field to alter the internal crystal field around lanthanide ions is critical to the modification of emission. Specifically, some factors such as temperature and electric fields cause changes in the symmetry of crystal structure [9-16]. In general, the probability of multi-phonon assisted nonradiative electron relaxation increases at elevated temperature, and the corresponding luminescence intensity weakens. In some current studies, $\mathrm{Yb}^{3+} / \mathrm{Er}^{3+}\left(\mathrm{Tm}^{3+}\right.$ or $\left.\mathrm{Ho}^{3+}\right)$ doped fluoride nanocrystals have been reported with an attractive antithermal quenching phenomenon at higher temperatures. However, fluoride nanocrystals commonly exhibit low chemical and thermal stability, limiting their realistic applications. Therefore, investigation of the effect of antitemperature quenching in oxide composites is essential to the development of their applications. The thermal population plays a vital role in modifying the upconversion luminescence of lanthanide ions at elevated temperatures [17-19].

On the other hand, the electric field can induce the symmetric transformation of the ferroelectric crystal structure, leading to the luminescence modification of lanthanide ions. For example, Hao's group [20] realized electrically enhanced photoluminescence in an epitaxial $\mathrm{BaTiO}_{3}: \mathrm{Yb} / \mathrm{Er}$ thin film. Kwok's team [21] explored the tuning of luminescence by the electric field in the $\mathrm{Eu}^{3+}$ doped $0.94 \mathrm{Bi}_{0.5} \mathrm{Na}_{0.5} \mathrm{TiO}_{3}-0.06 \mathrm{BaTiO}_{3} \quad$ ceramics. The symmetry of the ferroelectric nanocrystal structure was attenuated by the electric field, which could induce the

College of Materials Science and Engineering, China Jiliang University, Hangzhou 310018, China

* Corresponding author (email: baigx@cjlu.edu.cn) 
ligand field transformation around the dopant. It is attractive to explore the dynamic process of luminescence and to promote its application in optical sensors. The above described modifications of luminescence in the thermal and electric fields will potentially lead to the development of new luminescent materials with high thermal stability, high emission efficiency and multimode sensing functions.

The studies of luminescence modulation in different field environments provide practical examples of such materials being applied for reversible sensing. Typically, a suitable matrix material would have excellent optical properties and wide operating temperature range. As a promising host material for upconversion luminescence, ferroelectric oxide has attracted wide attention due to its high physicochemical stability and low phonon energy [22-24]. $\mathrm{LiNbO}_{3}$ is a typical displacement type ferroelectric material with considerable remnant polarization, excellent piezoelectric, optoelectronic and nonlinear optical properties. At room temperature, the $\mathrm{LiNbO}_{3}$ lattice structure belongs to the $R 3 \mathrm{c}$ space group, consisting of a $\mathrm{Li}-\mathrm{O}$ triangular body and a $\mathrm{Nb}-\mathrm{O}$ octahedron along the $c$-axis of the hexagonal unit. Lithium ions play a leading role in polarization behavior. The shift of the $\mathrm{Li}$ ions is relative to the triangular oxygen along the $c$-axis upward or downward, leading to polarization. The niobium ions migrate slightly in the octahedron, contributing additionally to the polarization behavior. When an electric field is applied, the $\mathrm{Li} / \mathrm{Nb}-\mathrm{O}$ bond is distorted, leading to the electromechanical softness of the $\mathrm{LiNbO}_{3}$ lattice $[25-$ 27]. The excellent stability and versatility make the $\mathrm{LiNbO}_{3}$ ferroelectric composite suitable for devices used in harsh thermal and electric field environments. Therefore, the $\mathrm{LiNbO}_{3}$ nanocrystal composite could be selected as a good host for lanthanide ions [28,29].

In this article, the upconversion luminescence of $\mathrm{Yb}^{3+} / \mathrm{Tm}^{3+} / \mathrm{Ho}^{3+}$ tri-doped $\mathrm{LiNbO}_{3}$ nanocomposites in both thermal and electric fields was investigated. $\mathrm{LiNbO}_{3}$ nanocrystals incorporated into the glass matrix were used as the functional groups. The coupling between the ferroelectric oxides and lanthanide ions under the external fields was explored. The enhancement of upconversion luminescence was achieved via the application of the thermal and electric fields. Moreover, the luminescence modulation by thermal and electric fields has excellent reversibility and is nonvolatile. The potential physical mechanism of the tuning of luminescence in both thermal and electric fields was investigated. The repeatability of the luminescence tuning guarantees the practical application of the transparent nanocomposites. The significant and reversible modulation of upconversion luminescence in thermal and electric fields provides a great possibility for the development of storage and non-contact multimode sensing.

\section{EXPERIMENTAL SECTION}

The transparent multi-component glass was designed according to the standard glass phase diagram. The glass system was $\mathrm{Li}_{2} \mathrm{O}-\mathrm{Nb}_{2} \mathrm{O}_{3}-\mathrm{SiO}_{2}$, and the nanocrystal composites were developed with different molar configurations and the optimized composition was $35 \mathrm{Li}_{2} \mathrm{O}$ $25 \mathrm{Nb}_{2} \mathrm{O}_{5}-38.2 \mathrm{SiO}_{2}-1.5 \mathrm{Yb}_{2} \mathrm{O}_{3}-0.2 \mathrm{Tm}_{2} \mathrm{O}_{3}-0.1 \mathrm{Ho}_{2} \mathrm{O}_{3}$, labeled as LG. The $\mathrm{Yb}^{3+} / \mathrm{Er}^{3+}$ co-doped glass ceramics were prepared with the optimized composition of $35 \mathrm{Li}_{2} \mathrm{O}$ $25 \mathrm{Nb}_{2} \mathrm{O}_{5}-38.25 \mathrm{SiO}_{2}-1.5 \mathrm{Yb}_{2} \mathrm{O}_{3}-0.25 \mathrm{Er}_{2} \mathrm{O}_{3}$, labeled as LYE. $\mathrm{Yb}^{3+} / \mathrm{Tm}^{3+} / \mathrm{Ho}^{3+}$ and $\mathrm{Yb}^{3+} / \mathrm{Er}^{3+}$ were doped into samples in the form of the oxide. This particular system was designed to uniformly precipitate ferroelectric crystallites at crystallization temperatures. The raw material powders with $99.99 \%$ purity were completely mixed and placed in a corundum crucible. The mixture was placed in a muffle furnace at $1500^{\circ} \mathrm{C}$ for 40 min to melt into homogeneous liquid. The glass system had a high tendency to devitrify, so the melt-quenching method was employed to avoid crystallization of samples. The melt was poured onto a cold stainless steel mold and then pressed into a $\sim 1 \mathrm{~mm}$ sheet with another brass plate, which provided a fast cooling rate. After pressing, samples were annealed at $450^{\circ} \mathrm{C}$ for $180 \mathrm{~min}$ to remove stress. The annealed samples were subjected to two steps, preliminary nucleation at $580^{\circ} \mathrm{C}$ for $120 \mathrm{~min}$, and grain growth at $670^{\circ} \mathrm{C}$. The samples were divided into $6 \mathrm{~mm} \times 6 \mathrm{~mm}$ small squares and placed in a muffle furnace for heat treatment. The thickness of the sample after heat treatment was polished to $0.25 \mathrm{~mm}$. A low temperature conductive silver paint was used in the ferroelectric test. The samples were placed in a drying cabinet at $100^{\circ} \mathrm{C}$ for $40 \mathrm{~min}$ to cure the silver paint. After the ferroelectric polarization, the conductive silver paint on the surface of the samples was removed. Then the samples were subjected to optical measurements.

Differential scanning calorimetry (DSC) was performed to analyze the glass transition temperature and crystallization temperature of the samples using a differential thermal analysis (DTA 404PC, NETZSCH), with a heating rate of $10 \mathrm{~K} \mathrm{~min}^{-1}$. X-ray diffraction (XRD) patterns of the samples were acquired using the advanced X-ray diffractometer (D2 PHASER, Bruker) with $\mathrm{Cu}-\mathrm{Ka}$ radiation. Absorption spectra were measured by a UV-vis-NIR spectrophotometer (UV3600, Shimadzu Corporation), 
with a resolution of $1 \mathrm{~nm}$. The KAP-02 heating platform was employed for the variable temperature spectrum. Raman spectra were recorded with a $532 \mathrm{~nm}$ laser device (inVia, Renishaw). The hysteresis loops were recorded using a ferroelectric test system (Radiant Precision Premier II Technology). In order to avoid leakage, the polarization-electric (P-E) field loops were measured at a frequency of $10 \mathrm{kHz}$ in a silicone oil bath. The luminescence spectra were recorded by the fluorescence spectrometer (Fluorolog Fl-3-211, Jobin Yvon) and the excitation source was $980 \mathrm{~nm}$ laser diode (LD). The microstructure in the composite was recorded by transmission electron microscope (TEM, FEI Tecnai G2 F20 SWTINE).

\section{RESULTS AND DISCUSSION}

Referring to the DSC results of the precursor sample (Fig. 1a), a two-step heat treatment process was employed. First, a preheat treatment at $590^{\circ} \mathrm{C}$ for $120 \mathrm{~min}$ was performed to form crystal nucleus in the sample. Subsequent heat treatment at $680^{\circ} \mathrm{C}$ for $i$ min caused the nucleus to grow, and the samples were labelled as LG- $i$ $(i=0,60,120,180,240,300$ and 600). Fig. 1b-d show the structural measurement of the LG samples. Fig. 1b shows the XRD patterns of the samples LG-0 and LG-180. The XRD peak of LG-0 is in the shape of a taro, which indicates that LG-0 is amorphous. The diffraction pattern of LG-180 consists of sharp peaks and the peak positions are in line with those of the standard card (PDF\#20-0631) of the $\mathrm{LiNbO}_{3}$ pure phase. The size of the crystal grains calculated using the Scherrer's equation is about $6.65 \mathrm{~nm}$. Fig. 1c shows the (012) plane of the $\mathrm{LiNbO}_{3}$ nanocrystal structure. The position of the peak gradually shifts to the left, and the LG-600 shifts to the left by $0.125^{\circ}$ compared to LG-0. Referring to the Bragg equation, Fig. 1c reveals that the lattice constant is gradually increasing, suggesting that ions with larger radii have entered the lattice of $\mathrm{LiNbO}_{3}$ and/or located in the interstitial sites. Prolonging the heat treatment facilitates the doping of ions into the $\mathrm{LiNbO}_{3}$ lattice. The ionic radii of $\mathrm{Yb}^{3+}, \mathrm{Tm}^{3+}$, and $\mathrm{Ho}^{3+}$ are larger than those of $\mathrm{Li}^{+}$and $\mathrm{Nb}^{5+}$. When the doping ions enter the crystal lattice, the interplanar spacing becomes larger. TEM and high resolution TEM (HRTEM) images of the LG-180 sample are presented in Fig. $1 \mathrm{~d}$ and e. Fig. 1d shows the dispersion of nanoscale crystals in a glass matrix. HRTEM image (Fig. 1e) shows the (110)
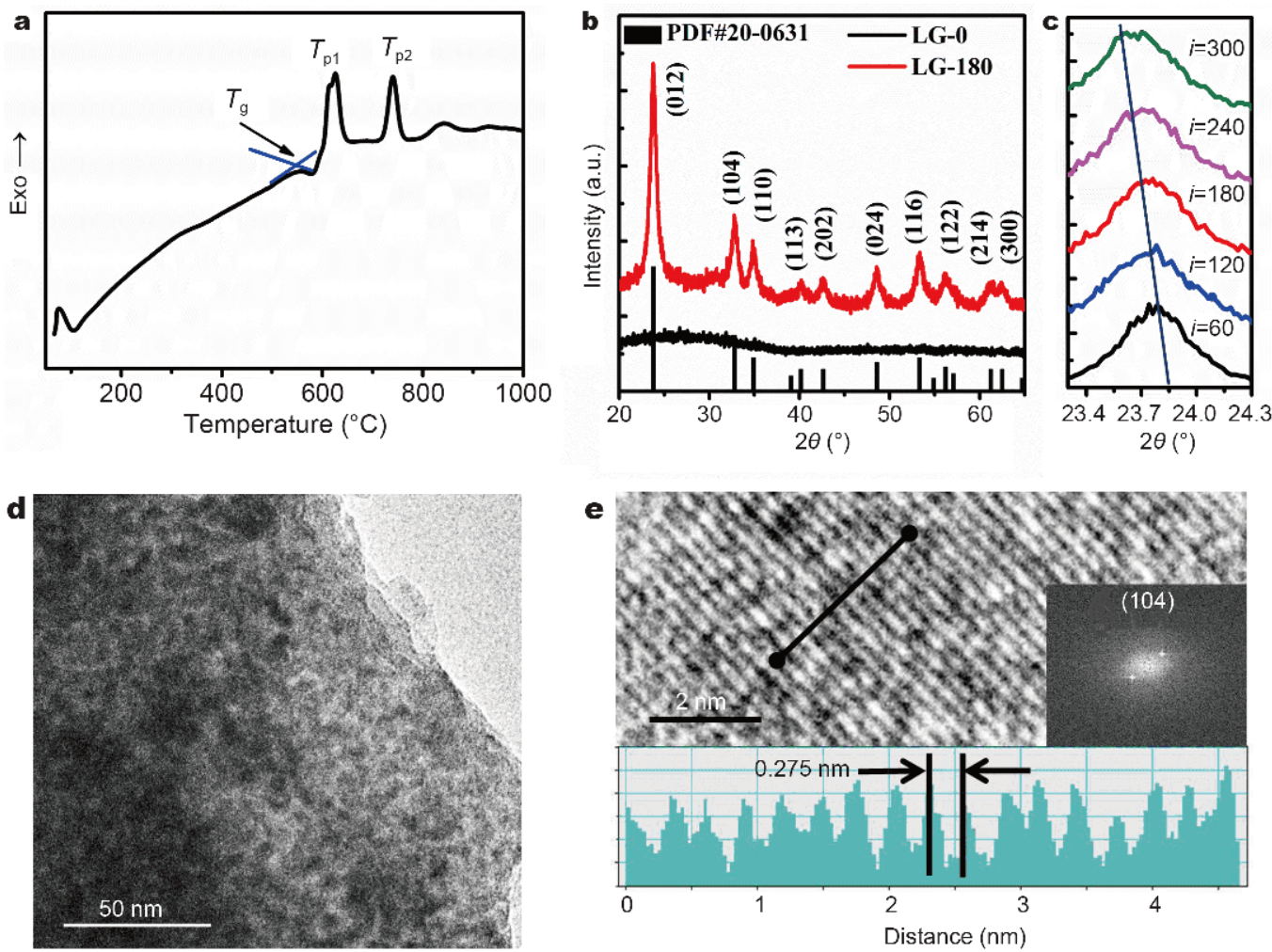

Figure 1 (a) DSC curve of the precursor glass sample. (b) XRD patterns of the glass and glass ceramics. (c) XRD patterns of the (012) crystal plane in the LG- $i$ samples $(i=60,120,180,240$ and 300). (d) TEM and (e) HRTEM image of the LG-180 sample. 
crystal plane of $\mathrm{LiNbO}_{3}$, and the interplanar spacing $d$ is about $0.256 \mathrm{~nm}$. The above study suggests that the prepared samples contain doped $\mathrm{LiNbO}_{3}$ nanocrystals.

Fig. 2a shows the schematic illustration of lanthanide ions entering the crystal lattice of a perovskite type $\mathrm{LiNbO}_{3}$ crystal. $\mathrm{Li}^{+}$and $\mathrm{Nb}^{5+}$ occupy octahedra positions in $C_{3}$ or near $C_{3 v}$ symmetrical point. When lanthanide ions enter the crystal lattice, they tend to form a $\left[\mathrm{LnO}_{6}\right]$ octahedron and replace the $\mathrm{Li}^{+}$and $\mathrm{Nb}^{5+}$ ions of $\mathrm{LiNbO}_{3}$. It can be seen in Fig. 2a that lanthanide ions replace $\mathrm{Li}^{+}$ and $\mathrm{Nb}^{5+}$ ions, and the dopants have larger ionic radii than the substituted ions. The doping ions pull the oxygen ligand inward along the doped ligand bond, causing the distortion of the lattice and the consequential formation of a distorted $\left[\mathrm{LnO}_{6}\right]$ octahedron. Lanthanide ions are suffering eccentric displacement along the $C_{3}$ axis of the oxygen octahedron. Fig. $2 b$ displays the absorption spectra of $\mathrm{Yb}^{3+} / \mathrm{Tm}^{3+} / \mathrm{Ho}^{3+}$ tri-doped and $\mathrm{Tm}^{3+} / \mathrm{Ho}^{3+}$ codoped samples. There are eight absorption peaks corresponding to the forced transitions of the $4 \mathrm{f}$ electric dipole from the ground state to different excited states in the $\mathrm{Yb}^{3+} / \mathrm{Tm}^{3+} / \mathrm{Ho}^{3+}$ ions. There is a strong absorption peak at $980 \mathrm{~nm}$ in the tri-doped sample, while it is not seen for the $\mathrm{Tm}^{3+} / \mathrm{Ho}^{3+}$ co-doped sample. Due to $\mathrm{Yb}^{3+}$ ions' excellent efficiency of energy transfer towards $\mathrm{Tm}^{3+} / \mathrm{Ho}^{3+}$ ions, they are used as a sensitizer to enhance the $\mathrm{Tm}^{3+}$ / $\mathrm{Ho}^{3+}$ emission. $\mathrm{Tm}^{3+}$ and $\mathrm{Ho}^{3+}$ have multiple energy levels, as shown in Fig. 2b. The absorption peaks at 688, 796 and $1205 \mathrm{~nm}$ correspond to the transitions of $\mathrm{Tm}^{3+}:{ }^{3} \mathrm{H}_{6}$ from the ground state to the excited state of ${ }^{3} \mathrm{~F}_{3}$ and ${ }^{3} \mathrm{~F}_{4}$. The other peaks at 456,544, 648 and $1205 \mathrm{~nm}$ are the activation from the ground state $\mathrm{Ho}^{3+}:{ }^{2} \mathrm{~F}_{2 / 7}$ to the higherenergy state of ${ }^{5} \mathrm{G}_{4},{ }^{5} \mathrm{~F}_{4}\left({ }^{5} \mathrm{~S}_{2}\right),{ }^{5} \mathrm{~F}_{5}$ and ${ }^{5} \mathrm{I}_{6}$ of the $\mathrm{Ho}^{3+}$ ions.

It is well known that the upconversion luminescence of the lanthanide ions can be modified by a thermal field.
The competition between the thermal population and quenching will determine the change trend of the luminescence at an elevated temperature. Thermal quenching of lanthanide ions will happen at high temperatures, that is, the probability of multi-phonon assisted non-radiative relaxation increases with temperature. Here, an interesting material with anti-thermal quenching property is observed. Fig. 3 shows the upconversion spectra of the LG-180 sample under $980 \mathrm{~nm}$ excitation. As shown in Fig. $3 \mathrm{a}$ and $\mathrm{b}$, the visible luminescence of the $\mathrm{Yb}^{3+} / \mathrm{Tm}^{3+} /$ $\mathrm{Ho}^{3+}$ tri-doped sample at 477, 547, 666 and $689 \mathrm{~nm}$ can be attributed to $\mathrm{Tm}^{3+}: \mathrm{G}_{4^{-}}{ }^{3} \mathrm{H}_{6}, \mathrm{Ho}^{3+}:{ }^{5} \mathrm{~F}_{4},{ }^{5} \mathrm{~S}_{2-}{ }^{5} \mathrm{I}_{8}, \mathrm{Ho}^{3+}$ : ${ }^{5} \mathrm{~F}_{5^{-}}{ }^{5} \mathrm{I}_{8}$ and $\mathrm{Tm}^{3+}:{ }^{3} \mathrm{~F}_{2,3^{-}}{ }^{3} \mathrm{H}_{6}$ transitions, respectively. The near-infrared luminescence at $796 \mathrm{~nm}$ is assigned to the $\mathrm{Tm}^{3+}:{ }^{3} \mathrm{H}_{4^{-}}{ }^{3} \mathrm{H}_{6}$ transition. The intensity variations of $\mathrm{Tm}^{3+}$ : ${ }^{1} \mathrm{G}_{4^{-}}{ }^{3} \mathrm{H}_{6}, \mathrm{Ho}^{3+}:{ }^{5} \mathrm{~F}_{4},{ }^{5} \mathrm{~S}_{2^{-}}{ }^{5} \mathrm{I}_{8}, \mathrm{Ho}^{3+}:{ }^{5} \mathrm{~F}_{5^{-}}{ }^{5} \mathrm{I}_{8}$ and $\mathrm{Tm}^{3+}:{ }^{3} \mathrm{~F}_{2,3^{-}}{ }^{3} \mathrm{H}_{6}$, $\mathrm{Tm}^{3+}:{ }^{3} \mathrm{H}_{4}{ }^{3} \mathrm{H}_{6}$ transitions are shown in Fig. $3 \mathrm{c}$ and $\mathrm{d}$. The intensities of the main blue emission around $477 \mathrm{~nm}$ and the near-infrared band around $796 \mathrm{~nm}$ gradually increase as the temperature increases from 293 to $573 \mathrm{~K}$. The emission band around $689 \mathrm{~nm}$ from $\mathrm{Tm}^{3+}:{ }^{3} \mathrm{~F}_{2,3^{-}}{ }^{3} \mathrm{H}_{6}$ transition is considerably weak at $293 \mathrm{~K}$ and the luminescent intensity is exceeding the green emission band around $547 \mathrm{~nm}$ at $573 \mathrm{~K}$. The intensities of the green and red emission bands around 547 and $666 \mathrm{~nm}$ firstly increase and then slightly decrease as the temperature increases. A good linear relationship is observed between the upcoversion emission intensity from $\mathrm{Tm}^{3+}:{ }^{3} \mathrm{~F}_{2,3}{ }^{3} \mathrm{H}_{6}, \mathrm{Tm}^{3+}$ : ${ }^{3} \mathrm{H}_{4^{-}}{ }^{3} \mathrm{H}_{6}$ and the temperature. The anti-thermal quenching is the result of the competition between the nonradiative relaxation and thermal populations. The antithermal quenching material has great significance for luminescence applications such as multi-color display materials, anti-counterfeiting and temperature sensing.

Fig. 4a shows the relationship between the upconver-
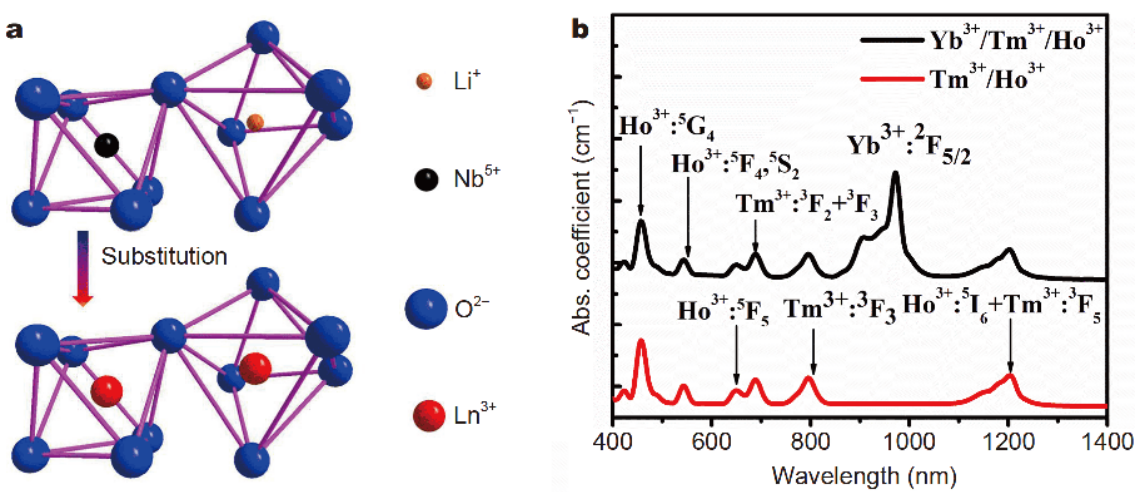

Figure 2 (a) Schematic illustration of lanthanide ions in the $\mathrm{LiNbO}_{3}$ lattice, $\mathrm{Ln}^{3+}=\mathrm{Yb}^{3+} / \mathrm{Tm}^{3+} / \mathrm{Ho}^{3+}$. (b) Absorption spectra of $\mathrm{Yb}^{3+} / \mathrm{Tm}^{3+} / \mathrm{Ho}^{3+} \operatorname{tri}^{-}$ doped and $\mathrm{Tm}^{3+} / \mathrm{Ho}^{3+}$ co-doped samples. 

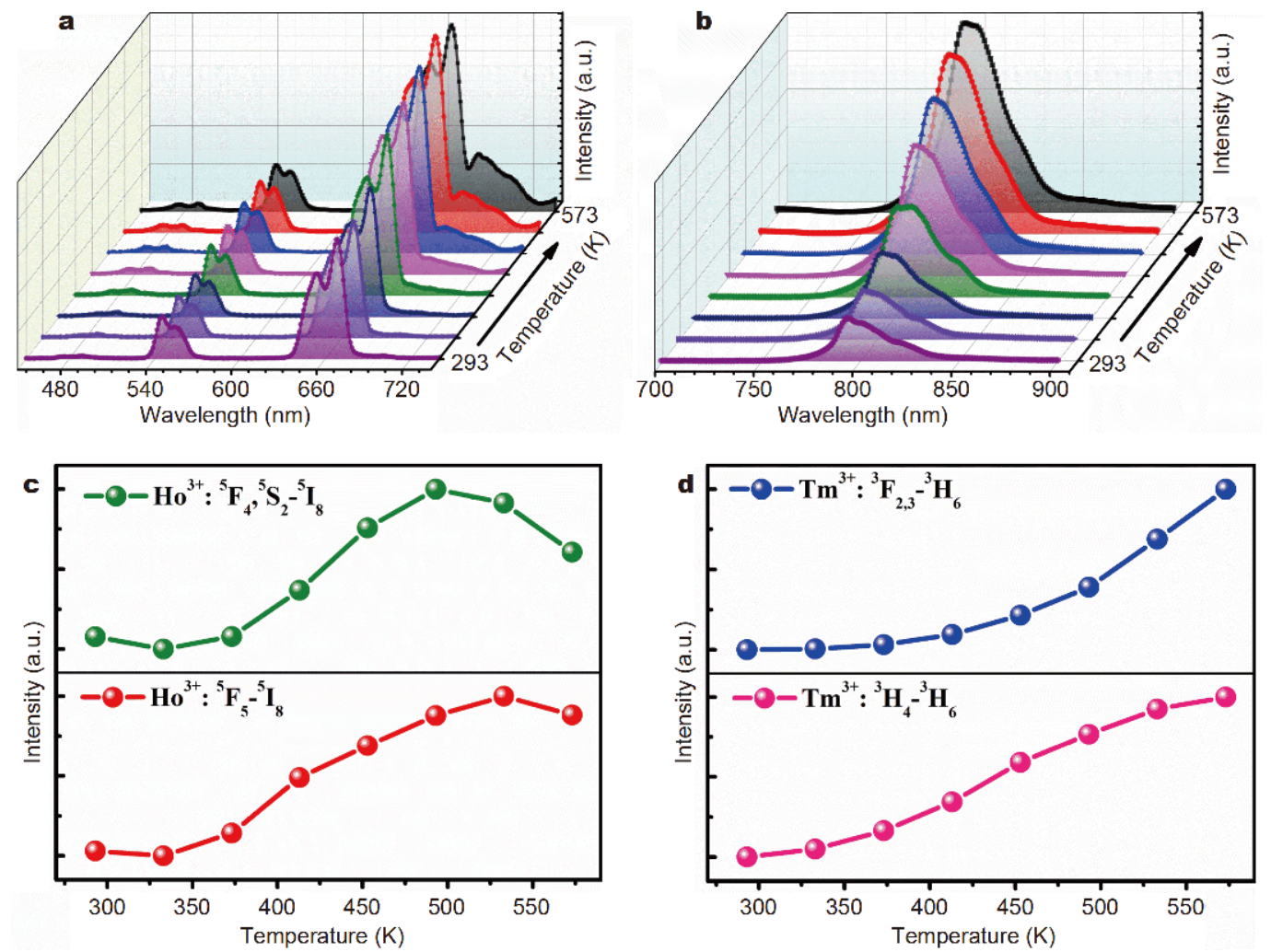

Figure 3 Temperature-dependent (a) visible and (b) near-infrared upconversion emission spectra of the LG-180 sample. Intensity variation of (c) $\mathrm{Ho}^{3+}:{ }^{5} \mathrm{~F}_{4},{ }^{5} \mathrm{~S}_{2}{ }^{-} \mathrm{I}_{8}, \mathrm{Ho}^{3+}:{ }^{5} \mathrm{~F}_{5}{ }^{5} \mathrm{I}_{8}$ and (d) $\mathrm{Tm}^{3+}:{ }^{3} \mathrm{~F}_{2,3}{ }^{3} \mathrm{H}_{6}, \mathrm{Tm}^{3+}:{ }^{3} \mathrm{H}_{4}{ }^{-3} \mathrm{H}_{6}$ at different temperatures (293-573 $\left.\mathrm{K}\right)$.

sion intensity of $\mathrm{Tm}^{3+}: \mathrm{H}_{4}{ }^{3}{ }^{3} \mathrm{H}_{6}$ and the excitation power density. The relationship between the luminescence intensity $(I)$ and the pump power density $(P)$ can be expressed as $I=P^{n}$, where $n$ is the number of photons participating in the corresponding upconversion processes. The number of photons of $\mathrm{Tm}^{3+}::^{3} \mathrm{H}_{4}{ }^{3} \mathrm{H}_{6}$ upconversion at $323,423,523 \mathrm{~K}$ are $1.232,1.407$ and 1.515 , respectively. When the temperature rises, more photons participate in the upconversion process of the $\mathrm{Yb}^{3+} / \mathrm{Tm}^{3+} /$ $\mathrm{Ho}^{3+}$ tri-doped ferroelectric nanocrystalline composite. Fig. $4 \mathrm{~b}$ shows the Raman spectra of the $\mathrm{Yb}^{3+} / \mathrm{Tm}^{3+} / \mathrm{Ho}^{3+}$ co-doped ferroelectric nanocomposites at 323, 423, $523 \mathrm{~K}$. As the temperature increases, there is no significant shift in the maximum phonon energy of the Raman peak from
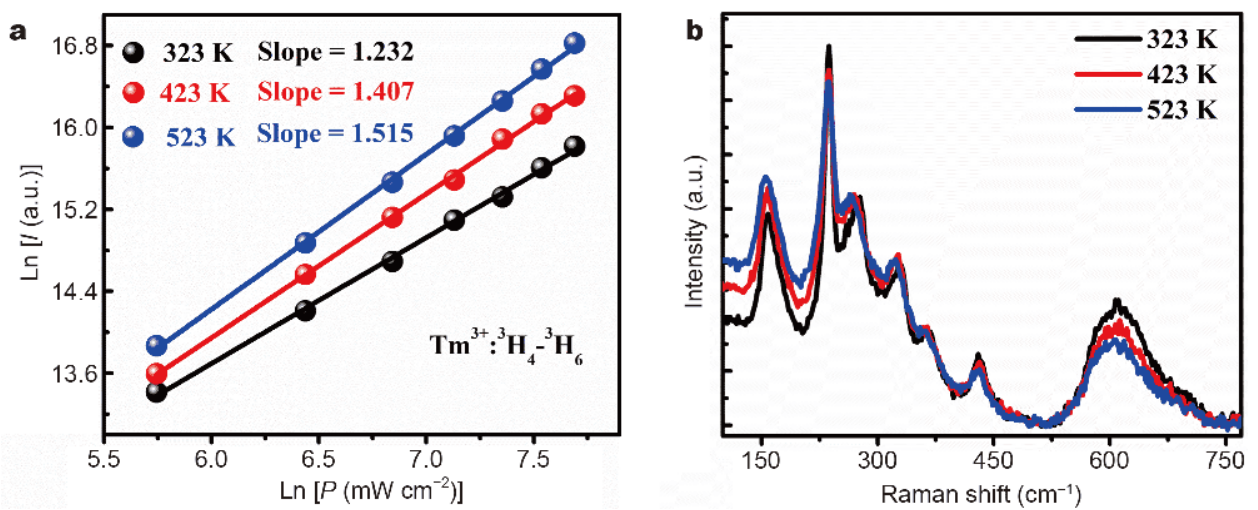

Figure 4 (a) Upconversion emission intensity of $\mathrm{Tm}^{3+}: \mathrm{H}_{4}{ }^{-}{ }^{3} \mathrm{H}_{6}$ transition and excitation power density at different temperatures. (b) The Raman spectra of $\mathrm{Yb}^{3+} / \mathrm{Tm}^{3+} / \mathrm{Ho}^{3+}$ tri-doped ferroelectric nanocomposite at different temperatures. 
524 to $760 \mathrm{~cm}^{-1}$, while the intensity of the Raman peak around $612 \mathrm{~cm}^{-1}$ has been weaken. The probability of non-radiative transition rate $\left(W_{\mathrm{NP}}\right)$ for the lanthanide ions can be expressed as $W_{\mathrm{NP}} \propto P(w)^{5 / 3}[30,31]$, where $P(w)$ represents the maximum phonon density of state of the sample. Therefore, the decrease in phonon density can reduce the probability of a non-radiative transition. According to the Raman spectra, around maximum phonon energy position of $\left(612 \mathrm{~cm}^{-1}\right)$ the ratio of the integrated area of the vibration peak to the total area is calculated to be $0.212,0.163$ and 0.135 at 323,423 and $523 \mathrm{~K}$, respectively. The maximum phonon energy density of the sample is the smallest at $523 \mathrm{~K}$, and the corresponding thermal quenching requires the largest activation energy. Therefore, the multi-phonon relaxation rates are reduced, and the probability of radiation transition is improved and conducive to the emergence of anti-thermal quenching.

A schematic illustration of the upconversion luminescence of the LG-180 sample excited by $980 \mathrm{~nm} \mathrm{LD}$ is presented in Fig. 5a. When the non-radiative transition is not negligible, the upconversion emission intensity $\left(I_{\mathrm{f}}\right)$ can be expressed as:

$I_{\mathrm{f}}=\left(I_{\mathrm{p}}\right)^{n} \times\left(W_{\mathrm{R}} /\left(W_{\mathrm{R}}+W_{\mathrm{NR}}\right)\right)$.

$I_{\mathrm{f}}$ and $I_{\mathrm{p}}$ are the upconversion luminance and pump power, respectively; $n$ is pump photons number required for the corresponding upconversion luminescence. $W_{\mathrm{NR}}$ and $W_{\mathrm{R}}$ represent the non-radiative transition rate and the radiation transition rate, respectively. Non-radiative relaxation plays an important role in the upconversion luminescence at elevated temperatures. At the same time, the influence of the thermal field is also an important factor during the heating process. The thermal population plays a leading role in the luminescence of 689 and $796 \mathrm{~nm}$ at elevated temperatures. Under the excitation of $980 \mathrm{~nm} \mathrm{LD}, \mathrm{Yb}^{3+}$ ions continuously absorb photons and convert the energy to populate the states of ${ }^{5} \mathrm{I}_{6},{ }^{5} \mathrm{~F}_{5},{ }^{5} \mathrm{~F}_{4}$ and ${ }^{5} \mathrm{~S}_{2}$ of $\mathrm{Ho}^{3+}$ and ${ }^{3} \mathrm{H}_{5},{ }^{3} \mathrm{~F}_{3},{ }^{3} \mathrm{~F}_{2}$ and ${ }^{1} \mathrm{G}_{4}$ of $\mathrm{Tm}^{3+}$. The thermal population participating in the ${ }^{2} \mathrm{~F}_{7 / 2}{ }^{2} \mathrm{~F}_{5 / 2}$ transition of $\mathrm{Yb}^{3+}$ is more significant with the influence of heat pumping. The population of electrons on the excitation level ${ }^{2} \mathrm{~F}_{5 / 2}$ of $\mathrm{Yb}^{3+}$ is increased, and then the energy transferred to $\mathrm{Ho}^{3+}$ and $\mathrm{Tm}^{3+}$ is improved. The probability that the electron transitions of $\mathrm{Ho}^{3+}$ and $\mathrm{Tm}^{3+}$ to the upper level becomes larger under the influence of the thermal filed. These processes can notably increase the population of $\mathrm{Ho}^{3+}$ and $\mathrm{Tm}^{3+}$ at the excited state level. The significance of thermal pumping exceeds the energy loss of the non-radiative transition, and thus establishing an anti-thermal quenching effect. The competition between the non-radiative relaxation and the thermal population results in a non-linear evolution in the luminescence intensity of $\mathrm{Ho}^{3+}:{ }^{5} \mathrm{~F}_{4},{ }^{5} \mathrm{~S}_{2}{ }^{5} \mathrm{I}_{8}$, and $\mathrm{Ho}^{3+}$ : ${ }^{5} \mathrm{~F}_{5}{ }^{-} \mathrm{I}_{8}$ transitions. During the heating process, the electron transitions between the thermal couplings levels increase based on heat pumping. The competition between the thermal population and the non-radiative transitions plays a crucial role in the upconversion emission process at high temperatures [32,33]. Hence the thermal population leads to an anti-thermal quenching phenomenon. To reflect the real-time color of upconversion luminescence at elevated temperatures, the luminescence intensity of the LG-180 sample was calculated
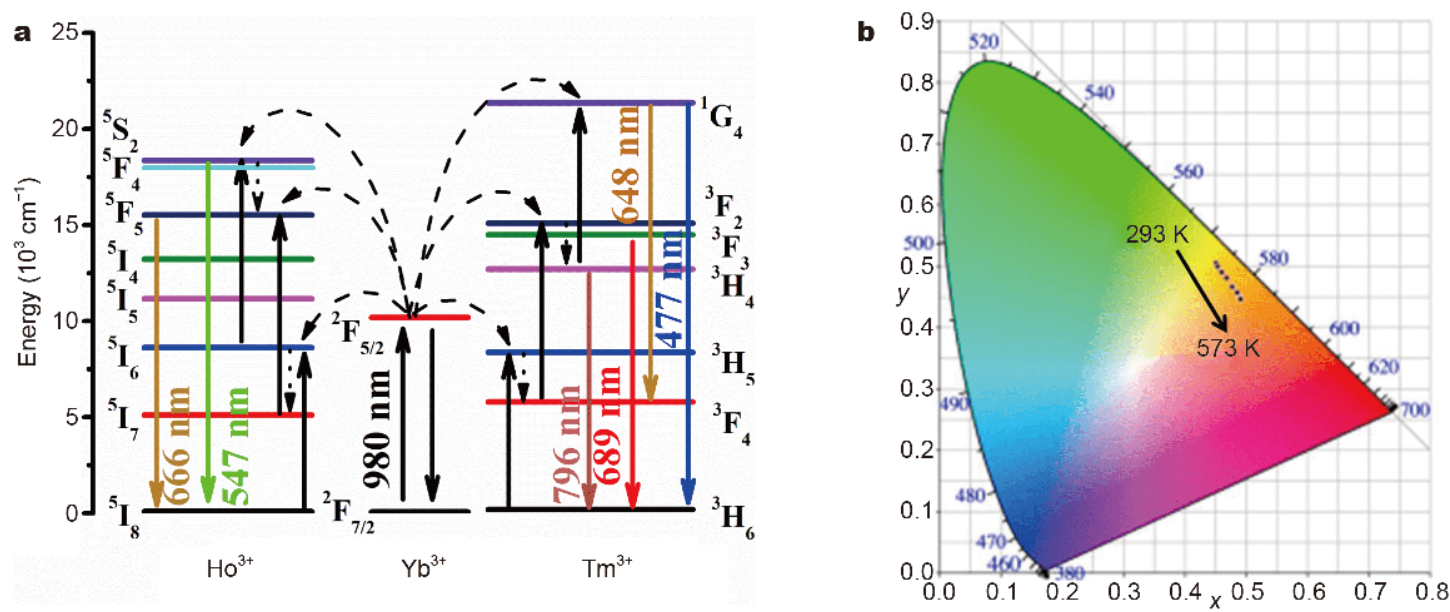

Figure 5 (a) The upconversion mechanism of $\mathrm{Yb}^{3+} / \mathrm{Tm}^{3+} / \mathrm{Ho}^{3+}$ tri-doped samples under excitation of $980 \mathrm{~nm}$ LD. (b) CIE chromaticity coordinates of upconversion luminescence at elevated temperatures. 
and marked in the color coordinates, as shown in Fig. 5b. In the CIE diagram, the coordinate position of the multicolor upconverted $\mathrm{Yb}^{3+} / \mathrm{Tm}^{3+} / \mathrm{Ho}^{3+}$ tri-doped samples has a tendency to shift from yellow to red. The coordinate position shift toward the visible region indicates that the $\mathrm{Yb}^{3+} / \mathrm{Tm}^{3+} / \mathrm{Ho}^{3+}$ doped samples have the characteristics of changing the luminescent color at different temperatures. The temperature dependency of the luminescent color has potential applications in colorful display and non-invasive temperature sensing.

The inclusion of $\mathrm{LiNbO}_{3}$ nanocrystals in a glass matrix improves the electrical resistance and leads to well transparent samples. The ferroelectric crystallites can be polarized in the electric field, and the ligand field of the luminescent ions will be modified subsequently [34,35]. The samples loaded under an electric field of $j \mathrm{kV} \mathrm{cm}^{-1}$ were respectively labeled as $\mathrm{E}-j(j=0,40,80,120$ and 160). The measured results of the luminescent and ferroelectric properties of the nanocrystal composite are shown in Fig. 6. Fig. 6a shows the P-E loops of the samples. The remnant polarization of the samples is continuously increasing with the remnant polarization of the sample loaded at $160 \mathrm{kV} \mathrm{cm}^{-1}$ being 4.1 times larger than that of the sample loaded at $40 \mathrm{kV} \mathrm{cm}^{-1}$. The pulsed electric field is applied to the sample, and then the cations are shifted at a picoscale along the $c$-axis driven by the electric field. This polarization originates from the lattice perturbations in the sample. Fig. $6 \mathrm{~b}$ and $\mathrm{c}$ present the upconversion luminescence of E-j. The enhancement factor of $\mathrm{Ho}^{3+}:{ }^{5} \mathrm{~F}_{4}$, ${ }^{5} \mathrm{~S}_{2}{ }^{5} \mathrm{I}_{8}, \mathrm{Ho}^{3+}:{ }^{5} \mathrm{~F}_{5}{ }^{-} \mathrm{I}_{8}$ and $\mathrm{Tm}^{3+}:{ }^{3} \mathrm{H}_{4}-{ }^{3} \mathrm{H}_{6}$ transition is up to 2.5, 3.9 and 2, respectively. Fig. $6 \mathrm{~d}$ shows that the luminescence intensity has a nearly linear relationship with the electric field. The symmetry of the ligand field becomes lower with an increased electric field. The luminescence of the lanthanide ions is sensitive to the symmetry of the crystal field, so external stimulus causes an effective enhancement of the luminescence. Multiple luminescence centered peaks provide an iterative test for the detection of the electric field.

To explain the potential physical mechanism of the electrical emission modulation, the structure change of the lanthanide ions doped ferroelectric nanocomposites in the electric field has been studied. Fig. 7 shows the structural changes in the E-j samples. As shown in Fig. 7a,
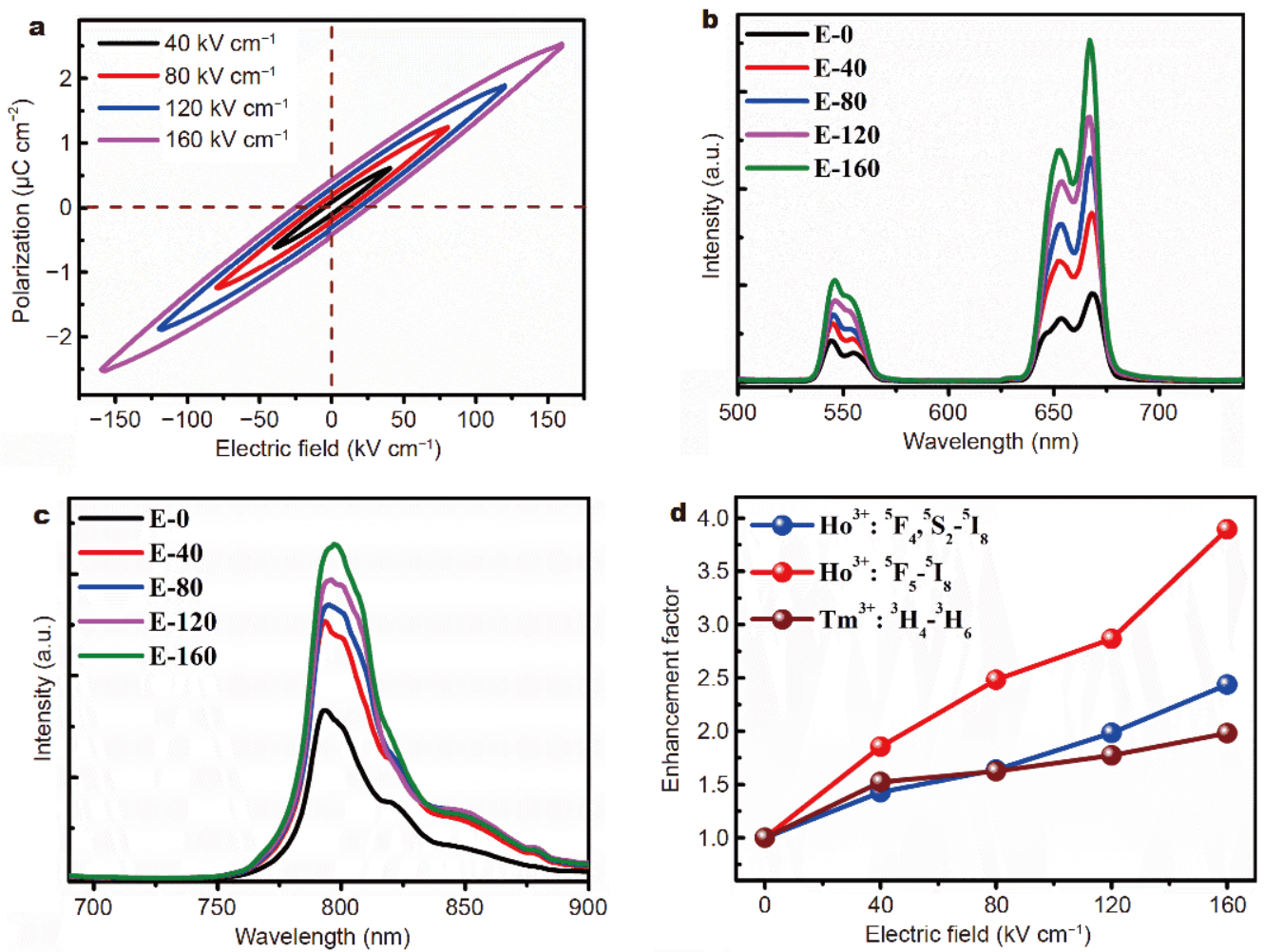

Figure 6 (a) Polarization-electric (P-E) field hysteresis loops for the LG-180 sample measured at a frequency of $10 \mathrm{~Hz}$. (b) Visible upconversion luminescence spectra of $E-j(j=0,40,80,120$ and 160) with the elevation of electric field. (c) Near-infrared luminescence spectra of E- $j$ with elevated electric field. (d) A graphical representation of the relationship between the polarized fluorescence and the electric field. 



Figure 7 (a) Relationship between the residual polarization and the electric field. (b) XRD patterns of the crystal plane (012) of the nanocrystallites in elevated electric fields. (c) Schematic illustration of the ligand field around the lanthanide ions after polarization. (d) Raman spectra of E-j samples in different electric fields.

the remnant polarization and the pulsed electric field have good consistency. The remnant polarization increases as the electric field loaded on the samples is increased. The (012) peak in the diffraction pattern of the E-j samples is shown in Fig. 7b. The XRD peak shifts to a larger angle. Considering the Bragg equation, the varying degree of contraction in the crystal lattice is caused by polarization, which is the aggravation of the ligand field around the lanthanide ions. Compared to E-0, the E-160 sample shows a right shift by $0.17^{\circ}$ of its (012) plane. The (012) peak of P-0 and P-200 is at $23.82^{\circ}$ and $23.99^{\circ}$, respectively. The interplanar spacing of E-0 and E-160 in $\mathrm{LiNbO}_{3}$ is 3.735 and $3.708 \AA$, respectively. The interplanar (012) spacing is reduced by $0.027 \AA$ with a loading of $200 \mathrm{kV} \mathrm{cm}^{-1}$. This result confirms the crystal structure changes. The active ions undergo displacement at picoscale from the original position, resulting in an attenuation of the symmetry of the crystal field around lanthanide ions. The cation and anion have ascending shift distances in the deformed octahedron, then the remnant polarization is more noticeable with the elevated electric field. In the E-j samples, the length of the original $\mathrm{Li} / \mathrm{Nb}-\mathrm{O}$ bond is transformed, and the bond lengths of
$\mathrm{Li}-\mathrm{O}$ and $\mathrm{Nb}-\mathrm{O}$ are both at nanoscale, so the lattice deformation of the ferroelectric crystallite is also performed sub-nanoscale [36]. Another explanation for the rightshift of the peak position might be the lattice shrinking induced by the alignment of nano-domains and the formation of ordered ferroelectric domains after the loading of the electric field, which effectively changes the symmetry of the crystal field around the lanthanide ions. The modification of the luminescence intensity causes the lattice distortion. Fig. $7 \mathrm{c}$ shows that the mechanism of the luminescence is modulated via the ferroelectric polarization. The ferroelectric nanocrystal lattice changes under the electric field, and then modifies the crystal field. The possible mechanism of regulating the upconversion luminescence intensity is the reduction in non-radiation loss, which is the result of the decreasing of phonon energy generated by the nanoscale motion of the active ions. Fig. $7 \mathrm{~d}$ shows the Raman spectra of the E- $j$ samples. The broad Raman mode near $750 \mathrm{~cm}^{-1}$ shifts to a smaller wavenumber with the enhancement of the electric field. This means the reduction of the maximum phonon energy of the entire system. The phonon density of the E- $j$ samples becomes lower. When the E- $j$ samples are excited 
by $980 \mathrm{~nm} \mathrm{LD}$, the energy required for lattice vibration is lessened based on the reduction in phonon density. As more excitation energy participates in the energy transition process of the lanthanide ions, more electrons are transited to the excited state level. The samples have more energy to populate the excited state ${ }^{5} \mathrm{I}_{6},{ }^{5} \mathrm{~F}_{5},{ }^{5} \mathrm{~F}_{4}$ and ${ }^{5} \mathrm{~S}_{2}$ of $\mathrm{Ho}^{3+}$ and ${ }^{3} \mathrm{H}_{5},{ }^{3} \mathrm{~F}_{3},{ }^{3} \mathrm{~F}_{2}$ and ${ }^{1} \mathrm{G}_{4}$ of $\mathrm{Tm}^{3+}$ after polarization. It is more possible to generate radiation relaxation. Therefore, the electric field effectively promotes the upconversion luminescence.

For comparison, the upconversion emission spectra of the $\mathrm{Yb}^{3+} / \mathrm{Er}^{3+}$ co-doped ferroelectric nanocrystalline composite have been collected at various temperatures and electric fields. Fig. 8a shows the temperature dependent upconversion emission spectra of the $\mathrm{Yb}^{3+} / \mathrm{Er}^{3+} \mathrm{co}-$ doped nanocomposite. As the temperature increases from 293 to $573 \mathrm{~K}$, there is no significant change in the central position of the luminescence peak, while the emission intensity of the $\mathrm{Yb}^{3+} / \mathrm{Er}^{3+}$ luminescence is extremely fluctuated under excitation of $980 \mathrm{~nm}$. The intensity of the luminescence peak at $530 \mathrm{~nm}$ is firstly increased at a slight rate, and then the intensity of emission decreases at a large rate. The relative intensity of the luminescence central peak at $554 \mathrm{~nm}$ continues to decrease, due to the thermal quenching. Different to the $\mathrm{Yb}^{3+} / \mathrm{Tm}^{3+} / \mathrm{Ho}^{3+}$ tridoped sample, the $\mathrm{Yb}^{3+} / \mathrm{Er}^{3+}$ co-doped system exhibits an enhanced multi-phonon relaxation rate and more prominent thermal quenching effect. The competition between the thermal population and the non-radiative transitions at high temperature is different in the different systems, due to the different energy levels and energy transfer processes $[32,33]$. Fig. $8 \mathrm{~b}$ shows the relationship between the upconversion intensity and the pump power density of $\mathrm{Er}^{3+}:{ }^{2} \mathrm{H}_{3 / 2}{ }^{4} \mathrm{H}_{15 / 2}$ at different temperatures. The slope is related to the number of photons participating in the $\mathrm{Er}^{3+}: \mathrm{H}_{3 / 2}{ }^{4} \mathrm{H}_{15 / 2}$ transition processes. The numbers of photons of $\mathrm{Yb}^{3+} / \mathrm{Er}^{3+}$ upconversion at $323,423,523 \mathrm{~K}$ are $1.592,1.475$ and 1.414 , respectively. The reduction in the number of photons involved in the $\mathrm{Yb}^{3+} / \mathrm{Er}^{3+}$ upconversion process is accompanied by the elevation of temperature. Fig. $8 \mathrm{c}$ and $\mathrm{d}$ show the upconversion emissions of the $\mathrm{Yb}^{3+} / \mathrm{Er}^{3+}$ co-doped ferroelectric nanocomposites with the elevation of electric field. The upconversion luminescence intensity is significantly enhanced with the
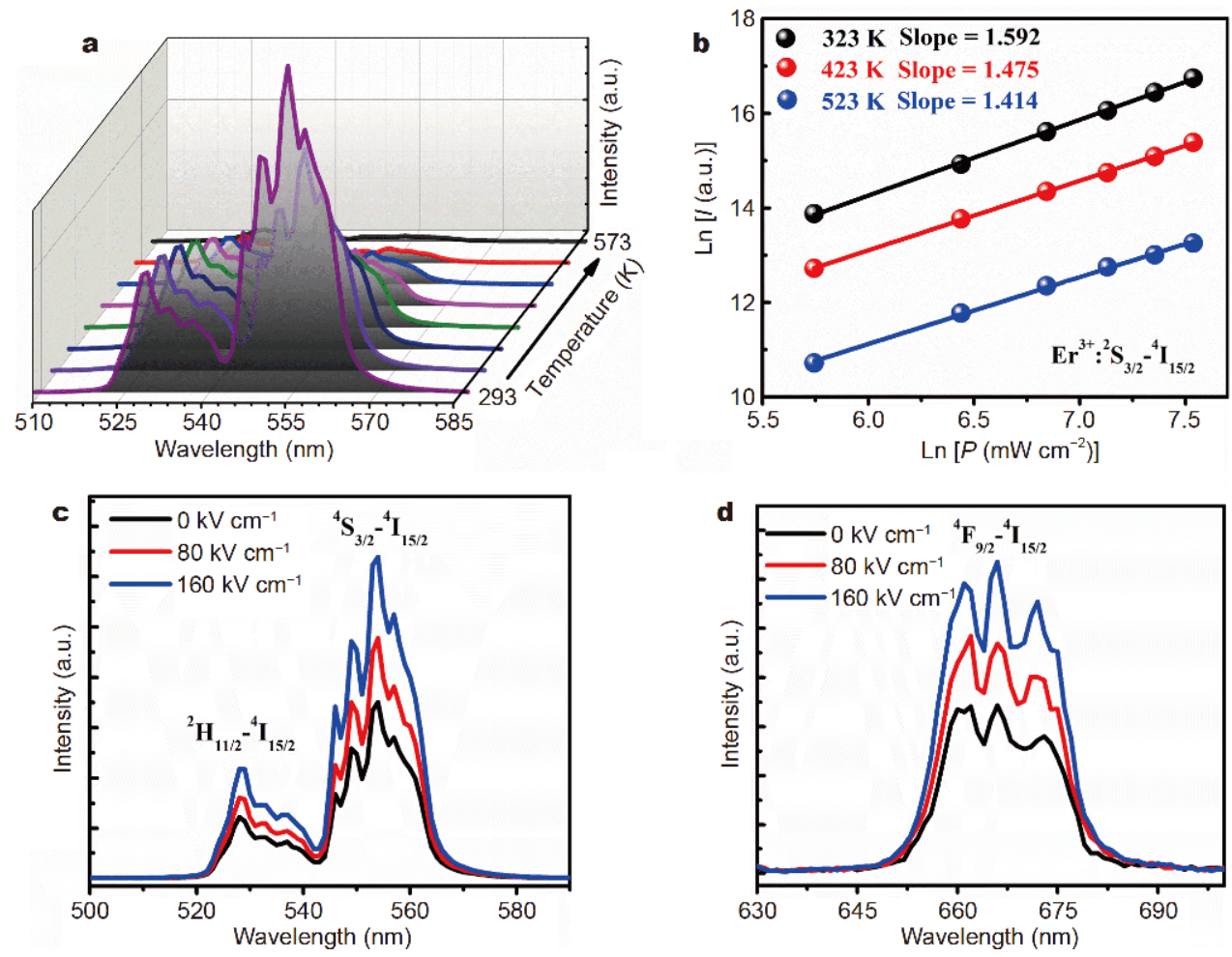

Figure 8 (a) Temperature dependent upconversion emission spectra of the $\mathrm{Yb}^{3+} / \mathrm{Er}^{3+}$ co-doped ferroelectric nanocrystalline composite. (b) Relationship between the upconversion emission intensity of $\mathrm{Er}^{3+}:{ }^{2} \mathrm{H}_{3 / 2}{ }^{4} \mathrm{H}_{15 / 2}$ transition and excitation power density at different temperatures. (c) The $\mathrm{Er}^{3+}:{ }^{4} \mathrm{~S}_{3 / 2}{ }^{4} \mathrm{I}_{15 / 2}$ transition of the $\mathrm{Yb}^{3+} / \mathrm{Er}^{3+}$ co-doped ferroelectric nanocrystalline composite in an increasing electric field. (d) The Er ${ }^{3+}:{ }^{4} \mathrm{~F}_{9 / 2}{ }^{4} \mathrm{I}_{15 / 2}$ transition of the $\mathrm{Yb}^{3+} / \mathrm{Er}^{3+}$ co-doped ferroelectric nanocrystalline composite with the elevation of the electric field. 
increase of the electric field. The enhancement factors of ${ }^{4} \mathrm{~S}_{3 / 2}{ }^{4} \mathrm{I}_{15 / 2}$ and ${ }^{4} \mathrm{~F}_{9 / 2}{ }^{4} \mathrm{I}_{15 / 2}$ transitions under $160 \mathrm{kV} \mathrm{cm}^{-1}$ are 1.82 and 1.85 , respectively. Due to the electric polarization, the probability of corresponding energy level transitions increases, which results in significant modification of the visible luminescence of $\mathrm{Er}^{3+}$ ions. In conclusion, the electrically enhanced upcoversion emission can be realized in both the $\mathrm{Yb}^{3+} / \mathrm{Tm}^{3+} / \mathrm{Ho}^{3+}$ and $\mathrm{Yb}^{3+} / \mathrm{Er}^{3+}$-doped samples.

The reversible and nonvolatile properties are critical to optoelectronic materials in many practical applications $[37,38]$. The reversibility and nonvolatility of the samples are shown in Fig. 9. Fig. 9a and b provide the nonvolatility testing of the samples under positive and negative electric fields. Fig. 9c illustrates the luminescence intensity of the peaks at 689 and $796 \mathrm{~nm}$ during temperature change. It can be clearly seen that the LG-180 material exhibits good repeatability in temperature measurement between 293 and $573 \mathrm{~K}$. During the temperature sensing process, the samples provide dual detection for temperature determination according to the evolution of the peak intensity at 689 and $796 \mathrm{~nm}$. As shown in Fig. 9d, the nanocomposite was loaded with a positive voltage of $80 \mathrm{kV} \mathrm{cm}^{-1}$, and the reverse voltage of $-40 \mathrm{kV} \mathrm{cm}^{-1}$ was reloaded afterwards. The luminescence intensity of the lanthanide ions alternates corresponds to the electric field intensity. Polarized luminescences at 547, 666, and $796 \mathrm{~nm}$ under electric field show excellent nonvolatility. The repeatability indicates that the structural changes inside the ferroelectric crystallites are reversible. Based on the above experiments, nanocrystalline composite has potential applications in the dual sensing of both thermal and electric fields.

\section{CONCLUSIONS}

This article reports that the upconversion luminescence properties of the $\mathrm{Yb}^{3+} / \mathrm{Tm}^{3+} / \mathrm{Ho}^{3+}$ tri-doped ferroelectric nanocomposites can be significantly enhanced by both thermal and electric fields. The results show that the reduced phonon density and thermal population play an important role in the upconversion luminescence process at elevated temperatures. The prepared sample with zero thermal quenching can be applied at high temperature. On the other hand, the electric field induced the enhanced transition of $\mathrm{Ho}^{3+}:{ }^{5} \mathrm{~F}_{4},{ }^{5} \mathrm{~S}_{2}{ }^{5} \mathrm{I}_{8}, \mathrm{Ho}^{3+}:{ }^{5} \mathrm{~F}_{5}{ }^{5} \mathrm{I}_{8}, \mathrm{Tm}^{3+}$ : ${ }^{3} \mathrm{H}_{4}{ }^{-} \mathrm{H}_{6}$ by $2.5,3.9$ and 2 times, respectively. XRD and
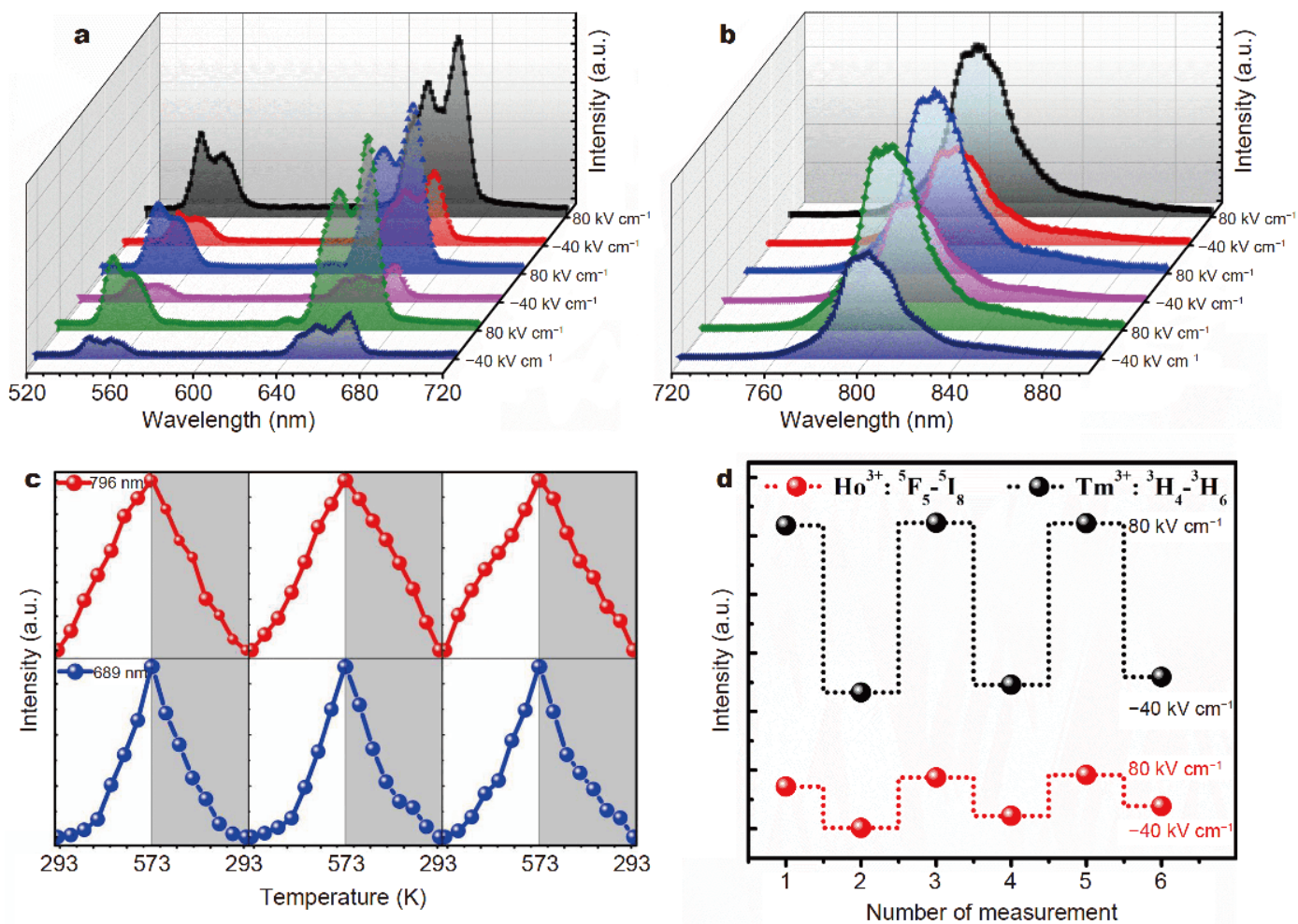

Figure 9 (a) Visible and (b) near-infrared luminescence modification through repeated loading of positive and negative electric fields. (c) Reversibility measurement of the intensity as a function of the thermal field temperature. (d) Nonvolatile testing. 
Raman results confirm the change in crystal structure with the influence of electric field. The electric field drives the picoscale displacement of the active cation relative to the oxygen layer, causing a change in the ligand field around lanthanide ions. The enhancement of the luminescence has good reversibility and nonvolatility in both thermal and electric fields. These findings not only promote the work of lanthanide ions doped ferroelectric nanocomposites to achieve luminescence modification, but also extend to potential applications in multi-environment detection and colorful display.

\section{Received 8 May 2019; accepted 3 July 2019;}

published online 2 August 2019

1 Cheng Y, Wang J, Qiu Z, et al. Multiscale humidity visualization by environmentally sensitive fluorescent molecular rotors. Adv Mater, 2017, 29: 1703900

2 Lv S, Shanmugavelu B, Wang Y, et al. Transition metal doped smart glass with pressure and temperature sensitive luminescence. Adv Opt Mater, 2018, 6: 1800881

$3 \mathrm{Lu} \mathrm{L}, \mathrm{Tu} \mathrm{D}$, Liu Y, et al. Ultrasensitive detection of cancer biomarker microRNA by amplification of fluorescence of lanthanide nanoprobes. Nano Res, 2017, 11: 264-273

4 Xia Z, Liu Q. Progress in discovery and structural design of color conversion phosphors for LEDs. Prog Mater Sci, 2016, 84: 59-117

5 Bai G, Tsang MK, Hao J. Luminescent ions in advanced composite materials for multifunctional applications. Adv Funct Mater, 2016, 26: 6330-6350

$6 \mathrm{Wu} \mathrm{Z}$, Bai G, Hu Q, et al. Effects of dopant concentration on structural and near-infrared luminescence of $\mathrm{Nd}^{3+}$-doped beta$\mathrm{Ga}_{2} \mathrm{O}_{3}$ thin films. Appl Phys Lett, 2015, 106: 171910

7 Wang Y, Zheng K, Song S, et al. Remote manipulation of upconversion luminescence. Chem Soc Rev, 2018, 47: 6473-6485

8 Lin $\mathrm{H}, \mathrm{Hu} \mathrm{T}$, Cheng $\mathrm{Y}$, et al. Glass ceramic phosphors: towards long-lifetime high-power white light-emitting-diode applicationsA review. Laser Photonics Rev, 2018, 12: 1700344

9 Bai G, Tsang MK, Hao J. Tuning the luminescence of phosphors: Beyond conventional chemical method. Adv Opt Mater, 2015, 3: 431-462

10 Zou H, Wang $\mathrm{X}, \mathrm{Hu} \mathrm{Y}$, et al. Optical thermometry based on the upconversion luminescence from $\mathrm{Er}$ doped $\mathrm{Bi}_{7} \mathrm{Ti}_{4} \mathrm{TaO}_{21}$ ferroelectric ceramics. J Mater Sci-Mater Electron, 2015, 26: 6502-6505

11 Meijerink A. Emerging substance class with narrow-band blue/ green-emitting rare earth phosphors for backlight display application. Sci China Mater, 2019, 62: 146-148

12 Wong MC, Chen L, Tsang MK, et al. Magnetic-induced luminescence from flexible composite laminates by coupling magnetic field to piezophotonic effect. Adv Mater, 2015, 27: 4488-4495

13 Zheng $\mathrm{M}$, Sun $\mathrm{H}$, Chan $\mathrm{MK}$, et al. Reversible and nonvolatile tuning of photoluminescence response by electric field for reconfigurable luminescent memory devices. Nano Energy, 2019, 55: 22-28

14 Pan E, Bai G, Lei L, et al. The electrical enhancement and reversible manipulation of near-infrared luminescence in $\mathrm{Nd}$ doped ferroelectric nanocomposites for optical switches. J Mater Chem C, 2019, 7: 4320-4325

15 Zhou B, Shi B, Jin D, et al. Controlling upconversion nanocrystals for emerging applications. Nat Nanotech, 2015, 10: 924-936

16 Lin J, Xu J, Liu C, et al. Effects of compositional changes on upconversion photoluminescence and electrical properties of leadfree Er-doped $\mathrm{K}_{0.5} \mathrm{Na}_{0.5} \mathrm{NbO}_{3}-\mathrm{SrTiO}_{3}$ transparent ceramics. J Alloys Compd, 2019, 784: 60-67

17 Zhang H, Peng D, Wang W, et al. Mechanically induced light emission and infrared-laser-induced upconversion in the Er-doped CaZnOS multifunctional piezoelectric semiconductor for optical pressure and temperature sensing. J Phys Chem C, 2015, 119: 28136-28142

18 Pan E, Bai G, Zhou J, et al. Exceptional modulation of upconversion and downconversion near-infrared luminescence in $\mathrm{Tm} /$ $\mathrm{Yb}$-codoped ferroelectric nanocomposite by nanoscale engineering. Nanoscale, 2019, 11: 11642-11648

19 Debasu ML, Ananias D, Pastoriza-Santos I, et al. Nanothermometry: All-in-one optical heater-thermometer nanoplatform operative from 300 to $2000 \mathrm{~K}$ based on $\mathrm{Er}^{3+}$ emission and blackbody radiation. Adv Mater, 2013, 25: 4817

20 Hao J, Zhang Y, Wei X. Electric-induced enhancement and modulation of upconversion photoluminescence in epitaxial $\mathrm{BaTiO}_{3}: \mathrm{Yb} / \mathrm{Er}$ thin films. Angew Chem Int Ed, 2011, 50: 68766880

21 Khatua DK, Kalaskar A, Ranjan R. Tuning photoluminescence response by electric field in electrically soft ferroelectrics. Phys Rev Lett, 2016, 116: 117601

22 Wu J, Qin N, Bao D. Effective enhancement of piezocatalytic activity of $\mathrm{BaTiO}_{3}$ nanowires under ultrasonic vibration. Nano Energy, 2018, 45: 44-51

$23 \mathrm{Wu} \mathrm{J}, \mathrm{Xu} \mathrm{Q}$, Lin $\mathrm{E}$, et al. Insights into the role of ferroelectric polarization in piezocatalysis of nanocrystalline $\mathrm{BaTiO}_{3}$. ACS Appl Mater Interfaces, 2018, 10: 17842-17849

24 Zhang Y, Jie W, Chen P, et al. Ferroelectric and piezoelectric effects on the optical process in advanced materials and devices. Adv Mater, 2018, 30: 1707007

25 Spanier JE, Fridkin VM, Rappe AM, et al. Power conversion efficiency exceeding the Shockley-Queisser limit in a ferroelectric insulator. Nat Photon, 2016, 10: 611-616

26 Dong H, Sun LD, Yan CH. Energy transfer in lanthanide upconversion studies for extended optical applications. Chem Soc Rev, 2015, 44: 1608-1634

27 Jiang J, Bai ZL, Chen ZH, et al. Temporary formation of highly conducting domain walls for non-destructive read-out of ferroelectric domain-wall resistance switching memories. Nat Mater, 2018, 17: 49-56

28 Timpu F, Sendra J, Renaut C, et al. Lithium niobate nanocubes as linear and nonlinear ultraviolet Mie resonators. ACS Photonics, 2019, 6: 545-552

29 Cui A, De Wolf P, Ye Y, et al. Probing electromechanical behaviors by datacube piezoresponse force microscopy in ambient and aqueous environments. Nanotechnology, 2019, 30: 235701

30 Layne CB, Weber MJ. Multiphonon relaxation of rare-earth ions in beryllium-fluoride glass. Phys Rev B, 1977, 16: 3259-3261

31 Komaraiah D, Radha E, James J, et al. Effect of particle size and dopant concentration on the Raman and the photoluminescence spectra of $\mathrm{TiO}_{2}: \mathrm{Eu}^{3+}$ nanophosphor thin films. J Lumin, 2019, 211 : 320-333

$32 \mathrm{Lu} \mathrm{H}, \mathrm{Hao} \mathrm{H}, \mathrm{Gao} \mathrm{Y}$, et al. Optical sensing of temperature based on non-thermally coupled levels and upconverted white light emission of a $\mathrm{Gd}_{2}\left(\mathrm{WO}_{4}\right)_{3}$ phosphor co-doped with in $\mathrm{Ho}(\mathrm{III}), \mathrm{Tm}(\mathrm{III})$, and $\mathrm{Yb}(\mathrm{III})$. Microchim Acta, 2017, 184: 641-646 
33 Xing L, Xu Y, Wang R, et al. Influence of temperature on upconversion multicolor luminescence in $\mathrm{Ho}^{3+} / \mathrm{Yb}^{3+} / \mathrm{Tm}^{3+}$-doped $\mathrm{LiNbO}_{3}$ single crystal. Opt Lett, 2013, 38: 2535-2537

34 Zou $\mathrm{H}, \mathrm{Yu} \mathrm{Y}, \mathrm{Li}$ J, et al. Photoluminescence, enhanced ferroelectric, and dielectric properties of $\mathrm{Pr}^{3+}$-doped $\mathrm{SrBi}_{2} \mathrm{Nb}_{2} \mathrm{O}_{9}$ multifunctional ceramics. Mater Res Bull, 2015, 69: 112-115 Wu X, Liu C, Tse MY, et al. Luminescent-electrical-magnetic performances of sol-gel-derived $\mathrm{Ni}^{2+}$-modified $\mathrm{Bi}_{0.5} \mathrm{Na}_{0.5} \mathrm{TiO}_{3}$. J Mater Sci-Mater Electron, 2017, 28: 12021-12025 Li L, Li Y, Zhao X. Interaction between Bi dopants and intrinsic defects in $\mathrm{LiNbO}_{3}$ from local and hybrid density functional theory calculations. Inorg Chem, 2019, 58: 3661-3669

Zheng K, Han S, Zeng X, et al. Rewritable optical memory through high-registry orthogonal upconversion. Adv Mater, 2018, 30: 1801726

38 Yu Y, Fang Z, Ma C, et al. Mesoscale engineering of photonic glass for tunable luminescence. NPG Asia Mater, 2016, 8: e318

Acknowledgements This work was supported by the National Natural Science Foundation of China (61705214) and Zhejiang Provincial Natural Science Foundation of China (LY19E020004).

Author contributions Bai G and Pan E designed and engineered the samples; Pan E performed the measurement; Pan E and Bai G performed the data analysis and theoretical analysis. All authors contributed to the general discussion and revision of the manuscript.

Conflict of interest The authors declare that they have no conflict of interest.

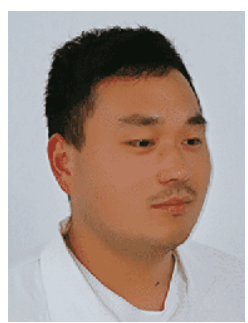

Er Pan obtained his BSc degree from Anhui University of Technology (2016). He is currently studying for a master's degree at the College of Materials Science and Engineering, China Jiliang University. His research focuses on luminescent sensing composite.

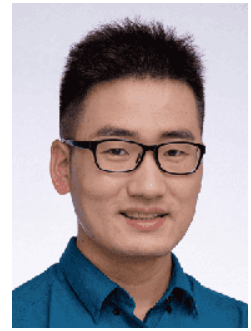

Gongxun Bai obtained his BSc degree from Huazhong University of Science and Technology (2008), MSc degree from Shanghai Institute of Optics and Fine Mechanics, Chinese Academy of Sciences (2011) and $\mathrm{PhD}$ degree from Hong Kong Polytechnic University (2016). Now he is a professor at the College of Materials Science and Engineering, China Jiliang University. His research focuses on low-dimensional optoelectronic materials and devices.

\section{通过热场和电场实现镧系离子掺杂铁电纳米复合 材料上转换发光的可逆增强}

\section{潘二, 白功勋 ${ }^{*}$, 马炳荣, 雷磊, 黄立辉, 徐时清}

摘要 调节镧系离子发光特性在传感、多彩显示、信息传递、防 伪等领域具有重要意义. 发光调控通常采用调控化学组分来实现, 然而化学调控法不利于发展多模式检测、多重信息防伪等. 本研 究以锞系离子掺杂铁电纳米复合材料为研究对象, 在热场和电场 两种外部环境刺激下实现增强发光. 在热场激励下样品呈现反猝 灭现象, 升温有效地增强了镧系离子的上转换近红外发光. 同时基 质中的铁电微晶晶格具有机电软弹性; 通过电场调节镧系离子周 围的晶体场结构实现了显著的发光增强, 这种调控具有优异的可 逆性和非易失性. 本研究表明, 可以通过热场和电场调控镧系离子 掺杂多功能无机铁电体纳米复合材料的发光性质, 这为设计高度 集成的发光传感器件和智能设备提供了重要参考, 特别是发展先 进的多模式检测材料. 